Bangladesh Journal of Neuroscience 2014; Vol. 30 (2): 77-83

\title{
Etiological Pattern of Dementia in Patients Attending Dementia Clinic in a Referal Hospital
}

\author{
MD. MASUD RANA ${ }^{1}$, IMRAN SARKER ${ }^{2}$, MD. SHAHADAT HOSSAIN ${ }^{2}$, MD. REZAUL KARIM KHAN ${ }^{3}$, \\ MD. RAFIQUL ISLAM ${ }^{3}$, ABU NASER RIZVI ${ }^{3}$, MD. AHSAN HABIB ${ }^{4}$, MD. NAZRUL ISLAM ${ }^{5}$, \\ ANIS AHMED ${ }^{1}$, MD. BAHADUR ALI MIAH ${ }^{6}$
}

\begin{abstract}
:
Background and objectives: Dementia is characterized by loss of or decline in memory and other cognitive abilities and reduces the lifespan of affected people. The number of people with Alzheimer's Disease and other dementias is increasing every year because of the steady growth in the older population and stable increment in life expectancy and it is expected to increase two-fold by 2030 and three-fold by 2050.In addition to Alzheimer's disease there are so many reversible and irreversible causes of dementia. This study was aimed to explore the different etiological factors related to dementia patients. Risk factors for dementia, co-morbid conditions were also included. Methods: This cross sectional study was carried out from 2009 to 2014 at dementia clinic (OPD), department of Neurology, Bangabandhu Sheikh Mujib Medical University (BSMMU). A total number of 166 dementia patients, as diagnosed by Diagnostic and Statistical Manual of Mental Disorders (DSM-IV) and confirmed by Mini Mental State Examination(MMSE) score were recruited in this study. Diagnosis of specific type of dementia was made on the basis of established criteria. Results: Alzheimer's disease(32.5\%) and Vascular dementia(31.9\%) were the most common etiological factor followed by Mixed dementia(19.9\%), PD with dementia(8.4\%) and others(7.2\%) like hypothyroidism, head injury, epilepsy etc. Increasing age, hypertension, diabetes mellitus, dyslipidemia, IHD, smoking are potential risk factors for dementia. Conclusion: This study concludes Alzheimer's disease and Vascular dementia are almost equally occurring dementia. There are also some potential risk factors for development of dementia whose modification can bring a great change in dementia treatment and functional outcome of this group of elderly people of Bangladesh.
\end{abstract}

Keywords: Dementia, Alzheimer's Disease(AD), Vascular dementia(VaD), Etiology, risk factors.

Introduction:

Dementia is a clinical syndrome characterized by "a global deterioration of mental functioning in its cognitive, emotional and conative aspects"1. Dementia is a syndrome consisting of a loss of several separable but overlapping intellectual abilities and present in a number of different combinations $^{2}$. Memory is the most common cognitive ability lost with dementia; $10 \%$ of persons $>70$ and $20-40 \%$ of individuals $>85$ years of age have clinically identifiable memory loss ${ }^{3}$. In addition to memory, other mental faculties are also affected in dementia; these include language, visuospatial ability, calculation, judgment, and problem solving. Neuropsychiatric and social deficits also develop in many dementia syndromes, resulting in depression, withdrawal, hallucinations, delusions, agitation, insomnia, and disinhibition. Diagnoses of dementia require some sort of memory deficit, although there are many dementias, such as frontotemporal

1. Medical Officer (Neurologist), Dept. of Neurology, BSMMU, Dhaka.

2. Resident, Phase B, Dept. of Neurology, BSMMU, Dhaka, Bangladesh.

3. Professor, Department of Neurology, BSMMU,Dhaka,Bangladesh.

4. Assistant Professor, Department of Neurology, BSMMU,Dhaka,Bangladesh.

5. Assistantss Professor, Department of Neurology, North-East Medical College, Sylhet,Bangladesh.

6. Associate Professor,Department of Neurology,BSMMU,Dhaka,Bangladesh 
dementia, where memory loss is not a presenting feature 4 . The reported frequency of dementia due to potentially reversible causes varies from 0 to $23 \%$ 5 . Cases of dementia are increasing due to longer life expectancy of the world population. Annual rate of progression to dementia is $15 \%$. Doubling the incidence of dementia above 65 yrs for every five yrs. Above the age of 85 yrs $50 \%$ have dementia ${ }^{3}$. Dementia affects $3-11 \%$ of the community dwelling adults who are more than 65 years of age ${ }^{6}$. By 2025 , $75 \%$ of estimated 1200 million people aged 60 years and older will be in developing countries. This growing of the developing world will pose a great medical, social and financial impact and will create an accelerated burden to infectious diseases and poverty ${ }^{3}$.It is estimated that the annual total cost of caring for a single $A D$ patient in an advanced stage of the disease is $>\$ 50,000$. The disease also exacts a heavy emotional toll on family members and caregivers ${ }^{4}$. Dementia is considered as the 3 rd most expensive disease in USA bearing a care cost of about US $\$ 100$ billion / year are direct care costs US $\$ 50$ billion / year. Major Burden is due to cost of long term home and institutional care. In UK care costs -US\$ 11 billion / year and direct care - US\$ 06 billion / year ${ }^{7}$. The prevalence of dementia in Bangladesh is $0.1 \%$ and among them $63.2 \%$ are male and $36.8 \%$ are female ${ }^{8}$. The overall prevalence of dementia is estimated in India was $3.36 \%{ }^{9}$. Alzheimer's disease (AD) is the most common subtype of dementia with, approximately two-third of dementia cases in over 65 years being diagnosed as $A D^{10}$. The other subtype of dementia includes vascular dementia or multi-infarct dementia (MID), Lewy body dementia, Parkinson's disease, Frontotemporal dementia, Creutzfeldt-Jakob disease etc.

The symptoms and problems linked to dementia can be best understood in three stages ${ }^{11}$ : (1) Early stage: (developed in 1-2 years): The early stage of dementia is often overlooked because the onset of dementia is gradual, it is often difficult to be sure exactly when it begins ${ }^{11}$. The person may for example:

- Have problems talking properly (language problems).
- Have significant memory loss - particularly for things that have just happened.

- Not know the time of day or the day of the week. (2) Middle stage: (developed in second to fifth year): As the disease progresses, limitations become clearer and more restricting. The person with dementia has difficulty with day-to-day living and:

- May become very forgetful - especially of recent events and people's names.

- Can no longer manage to live alone without problems.

- Is unable to cook, clean or shop.

(3) Late stage: (developed in fifth year or after): This stage is one of near total dependence and inactivity. Memory disturbances are serious and the physical side of the disease becomes more obvious. The person may:

- Have difficulty eating.

- Be incapable of communicating.

- Not recognize relatives, friends and familiar objects.

- Display inappropriate behavior in public.

- Be confined to a wheel chair or bed.

The DSM IV criteria (The Diagnostic and Statistical Manual for Mental Disorders, Fourth Edition) ${ }^{12}$ : recommends that factors A-D must all be satisfied to make a diagnosis for dementia

\section{A. The development of multiple cognitive deficits manifested by both}

1. memory impairment (impaired ability to learn new information or to recall previously learned information)

2. one (or more) of the following cognitive disturbances:

a. aphasia (language disturbance)

b. apraxia (impaired ability to carry out motor activities despite intact motor function)

c. agnosia (failure to recognize or identify objects despite intact sensory function)

d. disturbance in executive functioning (i.e., planning, organizing, sequencing, abstracting) 


\section{B. The cognitive deficits in Criteria A1 and A2 each}

1. cause significant impairment in social or occupational functioning

2. represent a significant decline from a previous level of functioning.

\section{The deficits do not occur exclusively during the course of a delirium.}

D. The disturbance is not better accounted for by another axis I disorder (for example, major depressive disorder, and schizophrenia)

The DSM IV criterion was developed by American Psychiatry Association ${ }^{12}$ and has been widely used in both clinical and epidemiological research. Advanced age remains the main risk factor for most forms of dementia ${ }^{13}$. Onset before 65 year of age is rare and, in the case of $A D$, often suggests a genetic cause. Single gene mutations at one of three loci (Beta amyloid precursor protein, presenilin1 and presenilin2) account for most of these cases ${ }^{14}$. For late-onset of $A D$, both environmental (lifestyle) and genetic factors are important. A common genetic polymorphism, the apolipoprotein $\mathrm{E}(\mathrm{apoE})$ gene e4 allele, greatly increases risk of going on to suffer from dementia; up to $25 \%$ of the population has one or two copies ${ }^{14}$. The evidence strongly establishes a causal role of cardiovascular risk factors and cardiovascular disease in the aetiology of dementia and $A D^{15}$. In short and longer latency incidence studies, smoking increases the risk for AD. However occasional negative finding have also been reported from large populations based prospective studies ${ }^{16,17}$. Those with high cardiovascular risk scores (incorporating hypertension, diabetes, hypercholesterolemia and smoking) have an increased risk for dementia incidence whether exposure is measured in midlife or a few years before dementia onset ${ }^{18-19}$. Recent studies report associations between metabolic syndrome and incident cognitive decline ${ }^{20}$, and insulin resistance and impaired executive function 21 . Diabetes is also reported as a risk factor ${ }^{22}$. There are some other reversible causes of dementia like hypothyroidism, deficiency of $B$ vitamins specially Vit $B_{1}$ and $B_{12}, N P H$, subdural haematoma, brain tumour, chronic infections, alcohol and other drug intoxication etc.

\section{Methods:}

This study was carried out in patients attending dementia clinic(OPD) of department of Neurology, Bangabandhu Sheikh Mujib Medical University (BSMMU),Dhaka from January 2009 to December 2012. A total number of 166 patients were enrolled in the study. This was a cross sectional study. The sampling technique was purposive (non- probability) sampling as per inclusion and exclusion criteria. Inclusion criteria were all patients with clinically diagnosed or documented to have dementia irrespective of age and sex; and attendants of participants, who gave consent and willing to comply with the study procedure. Acutely ill patients and patients unwilling to take part in the study were excluded.

Written informed consent was taken from the patients or their attendants before any interview. Data were collected by predesigned semi-structured questionnaire by the investigator consisting of medical history, physical examination, mini mental score examination, investigation as soon as possible after contact with the patient. Data obtained were recorded in predesigned data collection sheet.

i) Dementia was diagnosed by the criteria indicated by DSM-IV ${ }^{1}$. ii) Probable Alzheimer's disease was diagnosed by the criteria indicated by National Institute of Neurological Communicative Disorders and Stroke / Alzheimer's Disease and Related Disorders Association ${ }^{23}$. iii) Vascular dementia was diagnosed by DSM-IV criteria ${ }^{1}$. iv) Frontotemporal dementia was diagnosed by the clinical criteria ${ }^{24}$. v) Dementia with Lewy Bodies was diagnosed by Consensus Diagnostic criteria ${ }^{25}$. vi) Possible Creutzfeldt-Jakob disease (CJD) was diagnosed by the clinical criteria ( CDC Diagnostic criteria for possible Creutzfeldt-Jakob disease 2010$)^{26}$. vi) Others- Types of Dementia which were not fulfilling the established criteria were included here.

Data were processed and analyzed with the help of SPSS ( statistical Package for Social Sciences) Version 16.0. Quantitative data were expressed as mean and standard deviation, while qualitative data were expressed as frequency and percentage.

\section{Results:}

Age of demented patients ranged from 14 to 90 years with the mean $56.68 \pm 17.52$ years. Distributions of the age of the patients are shown in Table I. In this study $107(64.46 \%)$ patients were male and $59(35.54 \%)$ patients were female with a male to female ratio of 1.81:1 (Table II). 
Table-I

Distribution of patients by age $(n=166)$

\begin{tabular}{lcc}
\hline Age (years) & $\begin{array}{c}\text { Number of } \\
\text { patients }\end{array}$ & Percentage (\%) \\
\hline$<30$ & 6 & 3.6 \\
$31-40$ & 2 & 1.2 \\
$41-50$ & 17 & 10.2 \\
$51-60$ & 33 & 19.8 \\
$61-70$ & 54 & 32.5 \\
$>70$ & 54 & 32.5 \\
\hline \multicolumn{3}{c}{ Table-II } \\
\multicolumn{3}{c}{ Distribution of patients according to sex (n=166) } \\
Sex & Number of & Percentage (\%) \\
\multicolumn{3}{c}{ patients } \\
Male & 107 & 64.46 \\
Female & 59 & 35.54 \\
\hline
\end{tabular}

Table III showed the distribution of various risk factors associated with dementia. Only HTN was associated in $18.07 \%$ patients, DM in $3.01 \%$, Dyslipidemia in $1.81 \%$ and smoking in $15.06 \%$ of cases ; HTN and DM were in $10.24 \%$; HTN and Dyslipidemia in 3.01\% ; HTN,DM and Dyslipidemia in $3.61 \%$; ICSOL in $2.41 \%$; Head injury in $1.81 \%$; Epilepsy in $1.20 \%$; Hypothyroidism in $1.81 \%$; Post encephalitic state in $1.20 \%$ and $36.75 \%$ cases having no risk factors ( Table III).

\section{Table-III}

Distribution of risk factors among the study population $(n=166)$

\begin{tabular}{lcc}
\hline Risk Factors & $\begin{array}{c}\text { Number of } \\
\text { patients }\end{array}$ & Percentage (\%) \\
\hline HTN & 30 & 18.07 \\
DM & 5 & 3.01 \\
Dyslipidemia & 3 & 1.81 \\
Smoking & 25 & 15.06 \\
HTN with DM & 17 & 10.24 \\
HTN with Dyslipidemia & 5 & 3.01 \\
HTN with DM with & 6 & 3.61 \\
Dyslipidemia & & \\
ICSOL & 4 & 2.41 \\
Head injury & 3 & 1.81 \\
Epilepsy & 2 & 1.20 \\
Hypothyroidism & 3 & 1.81 \\
Post Encephalitis & 2 & 1.20 \\
No risk factors & 61 & 36.75 \\
\hline
\end{tabular}

Out of 160 patients $94.58 \%$ had no family history of dementia and only $54.2 \%$ had family history of dementia (Fig. 1).

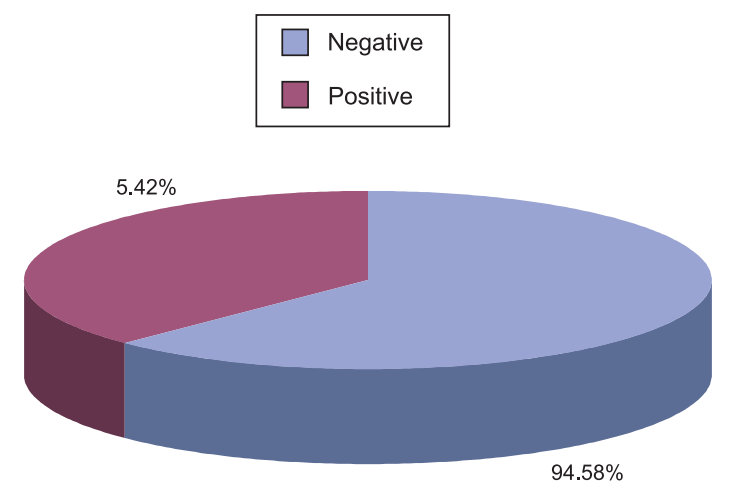

Fig.-1: Distributions of patients by family history of dementia

Regarding etiology, the study showed Alzheimer's disease as the highest number, next to it vascular dementia, followed by mixed dementia, PD with dementia and others (Table IV). Vascular dementia includes PSD, Multi infarct dementia, Small vessel disease; Mixed dementia comprises AD with VaD or PD and other dementias indicating secondary causes like ICSOL, Hypothyroidism, Epilepsy, Head injury, Post encephalitic state etc.

Table-IV

Distribution of etiological findings among the study population $(n=166)$

\begin{tabular}{lcc}
\hline Etiological findings & $\begin{array}{c}\text { No. of } \\
\text { patients }\end{array}$ & Percentage(\%) \\
\hline Alzheimer's Disease & 54 & 32.5 \\
Vascular dementia & 53 & 31.9 \\
Mixed dementia & 33 & 19.9 \\
PD with dementia & 14 & 8.4 \\
Others & 12 & 7.2 \\
\hline
\end{tabular}

\section{Discussion:}

Dementia is an acquired and persistent compromise in multiple cognitive domains that is severe enough to interfere with everyday functioning ${ }^{1}$. In western world between $60 \%$ and $70 \%$ of people with the dementia syndrome have Alzheimer's disease. A smaller number have other causes such as Lewy 
body dementia, frontotemporal dementia, PD, hypothyroidism and vitamin $\mathrm{B}_{12}$ deficiency ${ }^{27}$.

In this study, male was predominant than female which was $107(64.46 \%)$ and $59(35.54 \%)$ cases respectively. The ratio of male to female was 1.81:1.Similar result was reported by Hoffman et $\mathrm{al}^{28}$ that in subjects under 75 years the prevalence of dementia was slightly higher in men than in women. Ravaglia et al. ${ }^{29}$ reported that sex did not affect dementia risk which was inconsistent with the present study. In the present study, cases were taken from OPD(Dementia clinic) of Dept of Neurology, BSMMU where most of the patients were male.

Maximum patients(32.5\%) were in the age group 61-70 years. In this study $A D(54)$ and Vascular dementia(53) cases were closer in number and they were more common in age group 61-70 years. Similar result was reported by McCullagh et al. ${ }^{30}$ that after 65 years of age, the incidence and prevalence of dementia doubles every 5 years. It was reasoned that older individuals have longer exposure to putative environmental and genetic influences. Rimmer ${ }^{3}$ found a similar result and reported that cases of dementia are increasing due to longer life expectancy of the world population and $10 \%$ of all above 70 years has memory impairment.

Various risk factors associated with dementia among the study population was observed in this study. Only HTN was found in 30(18.07\%) patients and DM in $5(3.01 \%)$ cases. Similar result was reported by Ott et al. ${ }^{16}$ that DM almost doubled the risk of dementia. Patients treated with insulin were at highest risk of dementia ${ }^{16}$. Mizrahi et al. ${ }^{31}$ reported that non insulin dependent diabetes mellitus(NIDDM) is associated with an increased incidence of cognitive impairment which is consistent with the present study. In this study other co morbid conditions such as Dyslipidemia $3(1.81 \%)$, smoking 25(15.06\%), HTN and DM 17(10.24\%), HTN and Dyslipidemia in 5(3.01\%), HTN,DM and Dyslipidemia $3.61 \%$ were found The study also found some reversible causes of dementia like ICSOL 4(2.41\%), Head injury in $3(1.81 \%)$; Epilepsy in $2(1.20 \%)$; Hypothyroidism in $3(1.81 \%)$ cases.
Only $9(5.42 \%)$ cases gave positive family history. Similar finding was observed by Lindsay and Anderson $^{32}$. They mentioned that there was no statistically significant association for family history of dementia.

The distribution of major categories of dementia among the study population were recorded in this study. It was observed that Alzheimer's dementia $54(32.5 \%)$ and Vascular dementia (VaD) 53(31.9\%) were nearly same occurrence followed by mixed dementia, PD with dementia and other secondary dementias. But worldwide, AD is the most common form of dementia(70\%) followed by $\operatorname{VaD}(10-15 \%)^{33}$. These findings differ with this study. Here $\mathrm{VaD}$ has nearly equal prevalence in our population because of higher incidence of stroke. In this study after AD and $\mathrm{VaD}$ the most common etiological factor dementia were Mixed dementia 33(19.9\%) ;PD with Dementia 14(7.2\%); Other dementias $12(7.2 \%)$. Similar results were reported by lkeda et al. ${ }^{34}$ that vascular dementia was $47 \%$ followed by AD which was $35 \%$ and others $18 \%$. But most of the author claimed reverse. Hale ${ }^{35}$ mentioned that $A D$ is the most common cause of dementia, accounting for about half of all cases. Shelly et al ${ }^{36}$ observed $A D$ and $\operatorname{VaD} 52.6 \%$ and $24.1 \%$ respectively. Shaji et al ${ }^{9}$ reported that prevalence of $\mathrm{AD}$ and $\mathrm{VaD}$ in an urban population in Kerala, was $54 \%$ and $39 \%$ respectively. Reports of this study differed from those studies may be due to patient selection. Most of the studies were carried out on elderly patients without age limit. In this study patients were enrolled from neurology unit where most of them were stroke patients and its complication related. It may also be true that $A D$ is less common in our country. In this study secondary causes of dementia were ICSOL, Head injury Hypothyroidism, Epilepsy, Post Encephalitis state. Similar result was reported by Srikanth et al ${ }^{37}$. PD with dementia was found in $14(7.2 \%)$ cases which was supported by Hale ${ }^{35}$ that dementia may develop late in the disease, but not everyone with PD has dementia.

\section{Conclusion:}

Alzheimer's Disease is the most common etiological factor of dementia worldwide. Next to this is the Vascular dementia. Increasing age is the single most 
risk factor for development of dementia. Hypertension is associated with both vascular and degenerative dementia. Diabetes mellitus, Dyslipidemia, IHD are important co-morbid conditions. ICSOL, hypothyroidism, head injury, epilepsy are potentially reversible causes of dementia. Modification of risk factors and treatment of co morbid conditions can greatly improve the quality of life of these elderly demented patients.

\section{References:}

1. Fratiglioni L, Paillard-Borg S, Winblad B. An active and socially integrated lifestyle in late life might protect against dementia. Lancet Neurol 2004;3:343-53.

2. Ropper $\mathrm{AH}$, Brown $\mathrm{RH}$, editors. Adams and Victor's principles of neurology, $8^{\text {th }}$ ed. New York: The MacGraw-Hill Companies; 2005.

3. Elizabeth Rimmer. WHO should work to develop Alzheimer's standards. The Lancet 2003; 361:3.

4. Fauci AS, Kasper DL, Longo DL, Braunwald E, Hauser SL, Jameson JL, et al, editors. Harrison's principles of internal medicine, $17^{\text {th }}$ ed. New York: The MacGraw-Hill Companies; 2008.

5. Clarfield AM. The decreasing prevalence of reversible dementias: an updated metaanalysis. Arch Intern Med 2003;163:2219-29.

6. Evans DA, Funkenstein $\mathrm{HH}$, Albert MS, Scherr PA, Cook NR, Chown MJ,et al. Prevalence of Alzheimer's disease in a community population of older persons. Higher than previously reported. JAMA 1989; 262:2551-6.

7. Erkinjuntti, T, Clinical criteria for vascular dementia: the NINDS-AIREN criteria. Dementia1994; 5: 189-92.

8. Firoz AHM, Karim ME, Alam MF, Rahman AHMM, Zaman MM. Prevalence, Mental Care, Awarness and Attitude Towards Mental Illness in Bangladesh. Bangladesh Journal of Psychiatry 2006 Jun; 20(1):20-2.

9. Shaji S, Bose S and Verghese A. Prevalence of dementia in an urban population in Kerala, India. British Journal of Psychiatry, 2005; 186:136-40.
10. Colin Mathers, Matilde Leonardi. Global burden of dementia in the year 2000: summary of methods and data sources. 2000. Global Burden of Diseases 2000.

11. World Alzheimer Report. 2009. Alzheimer's Diseases International.

12. American Psychiatric Association. Diagnostic and Statistical Manual of Mental Disorders: DSM-IV, $4^{\text {th }}$ ed. Washington, DC: American Psychiatric Association; 1994.

13. Alzheimer's Disease Facts and Figures. Alzheimer's \& Dementia 2009; 5( 3).

14. Nalbantoglu J, Gilfix BM, Bertrand P, Robitaille Y, Gauthier S, Rosenblatt DS et al. Predictive value of apolipoprotein $E$ genotyping in Alzheimer's disease: Results of an autopsy series and an analysis of several combined studies. Annals of Neurology : Dec 1994 ;36(6):889-95.

15. Stampfer MJ. Cardiovascular disease and Alzheimer's disease: Common links. Journal of Internal Medicine 2006; 260(3):211-23.

16. Ott A, Slooter AJC, Hofman A, Van HF, Witteman JCM, Van BC et al. Smoking and risk of dementia and Alzheimer's disease in a population-based cohort study: The Rotterdam Study. Lancet 1998; 351(9119):1840-43.

17. Bursi F, Rocca WA, Killian JM, Weston SA, Knopman DS, Jacobsen SJ et al. Heart disease and dementia: A population-based study. American Journal of Epidemiology 2006; 163(2):135-41.

18. Perkins AJ, Hui SL, Ogunniyi A, Gureje O, Baiyewu O, Unverzagt FW et al. Risk of mortality for dementia in a developing country: The Yoruba in Nigeria. International Journal of Geriatric Psychiatry 2002; 17(6):566-73.

19. Llibre Rodriguez JJ, Ferri CP, Acosta D, Guerra M, Huang Y, Jacob KS et al. Prevalence of dementia in Latin America, India, and China: a population-based cross-sectional survey. Lancet 2008; 372(9637):464-74.

20. Yaffe K, Kanaya A, Lindquist K, Simonsick EM, Harris T, Shorr RI et al. The metabolic 
syndrome, inflammation, and risk of cognitive decline. Journal of the American Medical Association 2004; 292(18):2237-42.

21. Abbatecola AM, Paolisso G, Lamponi M, Bandinelli S, Lauretani F, Latmer Let al. Insulin resistance and executive dysfunction in older persons. Journal of the American Geriatrics Society 2004; 52(10):1713-18.

22. Ott A, Stolk RP, Van HF, Pols HAP, Hofman $A$, Breteler MMB. Diabetes mellitus and the risk of dementia: The Rotterdam Study. Neurology 1999; 53(9):1937-42.

23. McKhann, G, Drachman, D, Folstein, M, Katzman, R, Price, D, Stadlan, EM 1984, Clinical diagnosis of Alzheimer's disease: report of the NINCDS-ADRDA Work Group under the auspices of Department of Health and Human Services Task Force on Alzheimer 's disease, Neurology, 34,939-44.

24. Mckhann GM, Albert MS, Grossman M, Miller B, Dickson D, Trojanowski JQ. Clinical and pathological diagnosis of frontotemporal dementia: report of the work Group on frontotemporal dementia and Pick's disease. Arch Neurol, 2001; 58: 1803-9.

25. Mckeith IG, Dickson DW, LOWE J, Emre M, O'Brien JT, Feldman H. dementia with Lewy bodies: third report of the DLB consortium. Neurology.2005; 65: 1863-72.

26. CDC diagnostic criteria for possible CreutzfeldtJakob Disease2010. [ cited on 5 October 2010]. Available at: http://www.cdc.gov/ncidod/dvrd/ cjd/diagnostic_criteria.html

27. Breteler MM, Claus JJ, Van Duijn CM, Launer LJ, Hofman A. epidemiol Rev. 1992; 14: 59-80.

28. Hofman A, Rocca WA, Braync C, Breteler Mmb, Clarke M, Cooper B et al. The prevalence of Dementia in Europe: A collaborative study of 1980-1990 Findings. International Journal of Epidemiology. 1991; 20(03): 736-48.
29. Ravaglia G, Forti P, Maioli F, Martelli M, Servadei L, Brunetti $\mathrm{N}$ et al. incidence and etiology of Dementia in a large elderly Italian population. Neurology. 2005; 64: 1525-30.

30. McCullagh CD, Craig D, Mcllroy SP, Passmore AP. Risk factors for Dementia. Advances in psychiatric treatment. $2001 ; 7: 24-31$.

31. Mizrahi EH, Waitzman A, Blumstei T, Arad M, Adunsky A. Diabetes Mellitus predicts Cognitive impairment inpatients with ischemic stroke. Am J Alzheimer's Dis Other Demen. 2010; 25(4): 362-6.

32. Lindsay J, Anderson L. Dementia/Alzheimer's Disease. 2004.[Online]Viewed on $17^{\text {th }}$ March 2011. BMC Women's Health 2004;4(Suppl 1):S20 [Available at: http:// www.biomedcentral.com/1472-6874/4/S 1/ S20]

33. Mortimer JA, French LR, Hutton JT, Schumann LM. Head injury as a risk factor for Alzheimer's disease. Neurology. 1985; 35: 264.

34. Ikeda M, Hokoishi K, Maki N, Nebu A, Tachiban $\mathrm{N}$, Komori $\mathrm{K}$ et al. Increased prevalence of vascular dementia in Japan. Neurology. 2001; 57: 839-44.

35. Hale KL. Dementia overview . 2005 [online] . [cited on 5 October 2010]. Last Editorial review on 10/27/2005. Available at:http://www. emedicinehealth.com/dementia_overview/ page $2 \mathrm{~cm} \cdot \mathrm{html}$

36. Shelly BP, Khabouri JAL. The Spectrum of Dementia: Frequency, Causes and Clinical Profile. Dement and Geriatr Cogn Disord. 2007; 24(4): 280-7.

37. Srikanth S, Nagaraja AV. A prospective study of reversible dementias: Frequency, causes, clinical profile and results of treatment. Neurology India. 2005; 53(3): 291-4. 